\title{
Nesidioblastosis-associated hypoglycaemia presenting with prominent cardiac manifestations
}

\author{
Alfred Caruana Galizia, Stephen Fava, Rodney Foale
}

\section{Summary \\ We present a case of nesidioblastosis presenting with hyperinsulinaemic hypoglycaemia and electrocardiographic abnormalities.}

Keywords: nesidioblastosis, hypoglycaemia

Nesidioblastosis is a rare condition presenting with hyperinsulinaemic hypoglycaemia. It is probably inherited as an autosomal recessive trait. ${ }^{1,2}$ Pathologically, it is characterised by the finding of abnormal nests of endocrine tissue arising from pancreatic ducts.

\section{Case report}

A 40-year-old man was admitted to St Luke's Hospital on 7 February 1992 with a seven-day history of abdominal pain, vomiting, blurring of vision, lethargy and deteriorating urine output. On examination there was severe dehydration, a heart rate of 48 beats $/ \mathrm{min}$ and a blood pressure of $90 / 60 \mathrm{mmHg}$. Urine output during the first 80 minutes was $16 \mathrm{ml}$; central venous pressure was $3 \mathrm{~cm}$ water; blood urea and creatinine peaked at $32 \mathrm{mmol} / 1$ and $250 \mathrm{umol} / 1$, respectively. Serum potassium on admission was $5.9 \mathrm{mmol} / \mathrm{l}$, haemoglobin concentration $16.8 \mathrm{~g} / \mathrm{dl}$ and blood glucose $6.67 \mathrm{mmol} / 1$. The electrocardiogram (ECG) showed intermittent atrio-ventricular block with a junctional escape, and 3-4 mm downsloping ST segment depression in L1, aVL and V2-V6; $T$ waves were upright (figure). The patient's condition improved with intravenous rehydration and temporary right ventricular endocardial pacing; all biochemical parameters

Department of

Medicine, St Luke's

Hospital,

Guardamangia, Malta

AC Galizia

S Fava

\section{Director of}

Cardiology, St Mary's Hospital, London, UK

R Foale

Accepted 15 July 1995

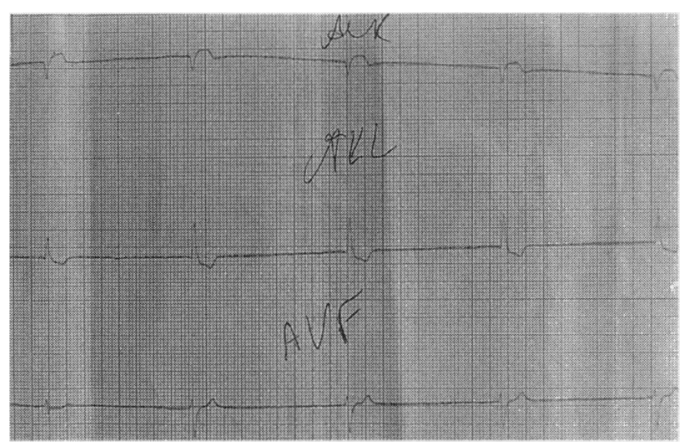

Figure Electrocardiographic tracing of the patient showing downsloping ST segment depression and a complete heart block. returned to normal within five days. The cardiac rhythm returned to normal after 40 hours but ST segment depression persisted for 17 days. There was no rise in serum creatine kinase activity. Ultrasound examination of the kidneys was normal.

The patient was re-admitted on 20 February 1992 with a sinus bradycardia of 48 beats/min accompanied by a sensation of faintness. Blood glucose was $5.5 \mathrm{mmol} / \mathrm{l}$. The bradycardia resolved spontaneously and the patient was discharged on 23 February. He was readmitted on 24 April in a state of mental confusion and with a blood glucose of $2.2 \mathrm{mmol} / 1$. The confusional state was immediately reversed by the intravenous administration of glucose. 24-Hour ambulatory ECG showed a prolonged PR interval and persistent ST segment depression of less than $2 \mathrm{~mm}$ but no rhythm disturbance. The $\mathrm{QT}_{\mathrm{c}}$ interval was within normal limits on all ECGs, including the 24-hour ambulatory recording. Echocardiography was also normal. Cardiac catheterisation studies revealed normal left ventricular dimensions and contractility and normal coronary arteries. Thyroid function tests and 24-hour urinary porphobilinogen, $\delta$-aminolevulinic acid and total porphyrins were normal. Ultrasound examination and computed tomography of the abdomen were also normal.

During the third hospitalisation the patient had repeated episodes of hypoglycaemia. Toxicology screen was negative. During one such episode of hypoglycaemia $(3.0 \mathrm{mmol} / \mathrm{l})$, serum insulin was $34.4 \mathrm{mU} / 1$ (reference range 2.8-13.5), C-peptide $1.01 \mathrm{nmol} / 1(0.18-0.52)$ and proinsulin $4.10 \mathrm{pmol} / 1(1.2-13.2)$. Serum insulin was estimated by radio-immunoassay (Pharmacia), C-peptide by an immunoassay (Incstar) and pro-insulin by an enzyme immunoassay.

Before these results were available, the patient died suddenly on 15 June 1992. Postmortem examination revealed a vitreous glucose level of $1.2 \mathrm{mmol} / 1$ and negative toxicology (including sulphonylureas and alcohol). The liver showed extensive fatty change with no evidence of hepatocellular necrosis or Mallory's hyaline. The pancreas was grossly normal. Microscopy revealed an increase in number and size of islets with foci of nesidioblastosis; no tumour could be found in spite of multiple sections. The heart was of normal size with no evidence of cardiomyopathy or ischaemic heart disease. 


\section{Discussion}

Our patient fulfilled the histological and biochemical criteria for a diagnosis of nesidioblastosis. Onset in adulthood has only rarely been reported. However, Fong et al suggest that it may be less rare than is commonly believed. ${ }^{3}$ Cases of hyperinsulinaemic hypoglycaemia in whom no insulinoma is demonstrated are often labelled as islet cell hyperplasia; it is possible that some of these may be due to nesidioblastosis that has been overlooked.

In our patient the major manifestations of recurrent hypoglycaemic episodes were electrocardiographic; there were conduction abnormalities and changes that are normally suggestive of ischaemia. Significant coronary artery disease was excluded angiographically. Hyperinsulinaemic states can be associated with a hypertrophic cardiomyopathy ${ }^{4,5}$; this is possibly related to the growth factor-like properties of insulin. However, there was no evidence of this in our patient on echocardiography, cardiac catheterisation or post-mortem studies. We believe that these electrocardiographic abnormalities were due to acute hypoglycaemia exacerbated in the initial presentation by volume depletion. These changes persisted even after correction (spontaneous or therapeutic) of hypoglycaemia. During the patient's first presentation blood glucose was normal on arrival at the emergency room; however, it is likely that there was a period of severe hypoglycaemia prior to arrival at hospital. We suggest that severe hypoglycaemia can result in prolonged electrocardiographic changes due to persistent intracellular hypoglycaemia or secondary metabolic abnormalities. Electrocardiographic changes have only rarely been reported in hypoglycaemia, ${ }^{6-8}$

1 Woo D, Scopes JW, Polak JM. Idiopathic hypoglycaemia in sibs with morphological evidence of nesidioblastosis of the pancreas. Arch Dis Child 1976; 51: 528-31.

2 Woolf DA, Leonard JV, Trembath RC, Pembrey ME Grant DB. Nesidioblastosis: evidence for autosomal recessive inheritance. Arch Dis Child 1991; 66: 529-30.

3 Fong TL, Warner NE, Kumar D. Pancreatic nesidioblastosis in adults. Diabetes Care 1989; 12: 108-14.

4 Harris JP, Ricker AT, Gray RS, Steed RD, Gutai JJ Reversible hypertrophic cardiomyopathy associated with nesidioblastosis. F Pediatr 1992; 120: 272-5.

5 Rizzo G, Arduini D, Romanini C. Accelerated cardiac growth and abnormal cardiac flow in fetuses of type I diabetic mothers. Obstet Gynaecol 1992; 80: 369-76.

6 Iga K, Hori K, Kitaguchi K, Matsumura T, Gen H, Tomonaga G, Tamamura $T$. Transient segmental asynergy of the left ventricle of patients with various clinical manifestations possibly unrelated to the coronary artery disease. $f p n$ Circ $\mathcal{J}$ 1991; 55: 1061-7.

\section{Learning points}

- hypoglycaemia should be considered as a cause of ECG changes, especially if other cases are excluded

- nesidioblastosis should be considered as a cause of hypoglycaemia even in adults

- the finding of an elevated serum insulin and C-peptide but normal proinsulin is suggestive of nesidioblastosis

Box 1

and there have been no previous reports of ST segment changes. In addition, coronary artery disease was not excluded angiographically in these reports.

It should be noted that the direct effect of insulin is to decrease coronary vascular resistance and increase left ventricular blood flow. ${ }^{9}$ Hence, the electrocardiographic changes seen in our patient and in those reported by Lindstrom $e t a l$ are likely to have been due to hypoglycaemia rather than hyperinsulinaemia per se.

Iscovich reported sudden cardiac death from hypoglycaemia in a patient with a duodenal insulinoma. ${ }^{10}$ Our patient died suddenly before the results of insulin, pro-insulin and Cpeptide were available. His immediate cause of death is likely to have been a cardiac rhythm disturbance, or due to a direct neuroglycopenic effect. Recently, Marques et $a l^{8}$ have implicated prolongation of the $\mathrm{QT}_{\mathrm{c}}$ as a possible mechanism of sudden death in hypoglycaemic states; however, there was no evidence of this in our patient.

We are indebted to Dr Bridget Ellul, Department of Pathology, St Luke's Hospital, for her valuable advice.

7 Lindstrom T, Jorfeldt L, Tegler L, Arnqvist HJ. Hypoglycaemia and cardiac arrhythmias in patients with type diabetes mellitus. Diabetes Med 1992; 9: 536-41.

8 Marques JLB, Cochrane T, Harris ND, Heller ST. QT interval prolongation during hypoglycaemia: a possible mechanism of sudden death. Diabetes Med 1995; suppl 1: S9 (abstr).

9 Liang CS, Doherty JU, Faillace R et al. Insulin infusion in conscious dogs. Effects on systemic and coronary hemodynamics, regional blood flows and plasm catecholamines. F Clin Invest 1982; 69: 1321-36.

10 Iscovich AL. Sudden cardiac death due to hypoglycaemia. Am $\mathcal{F}$ Emerg Med 1983; 1: 28-9. 